\title{
INFORMATIZATION OF EDUCATION. MEDIA EDUCATION AND MEDIA LITERACY
}

\begin{abstract}
Recent studies have shown that education in the 21st century cannot be imagined without using information and communication technologies, digital and media tools. As a result of teachers' training, it has become clear that there is a need to promote teachers, ICTs, media education and media literacy.

The article presents the informatization of education, which will promote the development of professional abilities and skills of teachers, lecturers, raising public awareness and improving the quality of education.

Keywords: Informatization of education, media education, media literacy, computer literacy, information and communication competence

Introduction: In modern education, a competency-based approach is gaining popularity, which is understood as implementing educational programs to develop the individual's ability to independently apply, in a specific context, the knowledge and skills acquired in their professional activities.

At present, there is a change in pedagogical paradigms when the primary purpose of the education system is the training of specialists of double competence: on the one hand, strictly connected with the profession, and on the other hand, capable of not only understanding the capabilities of information and communication technologies (ICT) but also using them, adapting to practical tasks, solving specialized problems arising in various fields human activities. Information technologies form the basis for forming general professional competencies of a modern specialist of any profile. Their use is a prerequisite for increasing the effectiveness of education, developing more effective approaches to learning, improving teaching methods.

The modern problem of informatization of the education system consists of creating all the technical conditions for the introduction of computer technology in the educational process and that teachers are mentally prepared to constantly improve their level of competence in the field of information and communication technologies. In this
\end{abstract}


regard, one of the essential areas is competence-based education in the field of information technology.

\subsection{Informatization of education as a factor in the development of society}

In the middle of the 20th century, technological progress and the growing dynamism of life led, on the one hand, to an increase in the needs of people in effective education, and on the other, to new methods of obtaining it. In the context of a significant restructuring of the baking education system, strengthening educational institutions' independence, the nascent variety of types of schools (training school, with specialized training, gymnasium, lyceum and college), the training of specialists has undergone significant changes. The tasks of developing creative potential, cognitive activity, and students' independence, shaping their business qualities and professional mobility have come to the fore. The social order of the company to train professionally competent specialists required a significant change in many components of the training system: goals, objectives, content, methods and organizational forms based on new technologies and training tools. One of the most significant innovative approaches to solving the problem of modernizing the education system and managing educational institutions was the informatization of education.

Informatization of education is the process of providing education with the methodology and practice of developing and optimizing the use of modern information and communication technologies focused on the implementation of the pedagogical and psychological goals of training and education.

Informatization of education is an integral part of informatization of society - the global social process, the peculiarity of which is that the dominant type of activity in the field of social production is the collection, accumulation, processing, storage, transmission, use of information carried out on the basis of modern computer technology and information exchange. The use of information technology can effectively promote students' enthusiasm and improve the active atmosphere of classroom teaching, broaden students' horizons, and enrich teaching contents (Robert, 2014, p. 10).

The informatization of education is regarded as an area of pedagogical science. This includes the subsystems of education and a combination of psychological, pedagogical, social, physiological, technical, scientific, and practical researches, which can create a certain type of integrity, providing the educational sector with the theory, methodology, and practice to perfect and optimize the use of ICT tools in comfortable and health-saving conditions (Gorokhova, 2018, p. 3). 
The Concept of the federal target program "Development of Education Informatization" defined strategic directions for the World's transition to the information society. The majority of citizens created optimal conditions for realizing rights and doubling information needs through the use of information resources. Among them, one of the main ones is the informatization of the entire general and special education system, enhancing the role of qualifications, professionalism, and creativity.

Often, informatization of education means the implementation of information and telecommunication technologies in the educational process. This is really important, having a decisive influence on improving education quality, but not the only area of education informatization. Informatization of education is a broader concept, which is a field of scientific and practical human activity aimed at using information and communication technologies and the means of collecting, storing, processing and optimal use of information, ensuring the systematization of existing and the formation of new knowledge to achieve the goals of training and education.

Informatization of education initiates the subsequent processes:

- improvement of the methodology and strategy for the choice of content, ways and structure varieties of coaching, education, akin to the tasks of developing the temperament of the scholar

- creation of methodological training systems focused on developing the learner's intellectual potential, the formation of skills to independently acquire knowledge, carry out information-educational, experimental research, and other types of information activities.

- improving the management system of the education system based on the use of automated data banks of scientific and pedagogical information, information and teaching materials and communication networks;

Informatization of education includes the following areas:

- creation and development of material and technical base, information and network infrastructure

- development and use of high-quality software and methodological support

- development of a modern approach to improving the effectiveness of training based on new information and communication technologies;

- training specialists with information and pedagogical culture.

The study of problems informatization of education involves using a particular conceptual apparatus, which can basically be considered established. Here are several generally accepted concepts of education informatization. 
Means of informatization of education are means of new information technologies (NIT), used together with educational-methodical, normative-technical and organizational-constructive materials, ensuring the implementation of optimal technology and their pedagogically appropriate use. The means of informatization of education are information technology, technical and communication tools, software, psychological and methodological support.

The information-subject environment with built-in elements of teaching technology - a set of conditions conducive to active information interaction between the teacher and the students, focused on the implementation of various types of activities (informationeducational, experimental-research) within the framework of specific teaching technology.

The information-subject environment with built-in elements of teaching technology includes means and technologies for collecting, accumulating, storing, processing, transmitting educational information, means for presenting and extracting knowledge, ensuring their interconnection and functioning of organizational structures of pedagogical impact.

Information and educational activity is an activity based on information interaction between students, parents, a teacher and the means of new information technologies aimed at achieving educational goals. At the same time, the following activities are supposed to be performed: registration, collection, accumulation, storage, processing of information about the studied objects, phenomena, processes; transfer of large volumes of data; interactive dialogue; management of real objects, control of the display on the screen of models of various things, phenomena, processes, automated control (selfcontrol) of the results of educational activities and correction according to the effects of control.

Management information systems ensure the flow of information flows between all educational process participants (students, teachers, administration, parents, community).

\subsection{Computer literacy, information culture, information and communication}

\section{competence}

The concepts of 'computer literacy' and 'information culture' changed their content at different stages of the development of society and education. 
In 1985, the first program of the school course, Fundamentals of Computer Science and Computer Engineering, proclaimed the formation of computer literacy of students, which includes the following components, as the specific educational goal

- the ability to communicate with a computer at a user level,

- compilation of simple computer programs at the level of understanding the basic principles of programming,

- a representation of the device and principles of computer operation;

- an idea of the areas of application and capabilities of computers, the social consequences of computerization.

A year after the publication of the first program, it became clear that teaching computer science goals cannot be strictly limited by computer literacy, and the goals themselves must be expanded. In the second program, lines of computer modelling and information technology were added. The following components were introduced into the concept of "computer literacy":

- understanding the device and functioning of the computer

- skills of competent setting tasks arising from practical activities for their solution with the help of computers;

- skills of a formalized description of the tasks, elementary knowledge of the methods of mathematical modelling, the ability to build simple mathematical models of the tasks;

- knowledge of the main algorithmic structures and the ability to apply this knowledge to build algorithms for solving problems according to their mathematical models;

- elementary skills in compiling computer programs according to the constructed algorithm in one of the high-level programming languages;

- understanding the basic principles underlying the functioning of information systems, and the skills of their qualified use to solve practical problems;

- the ability to correctly interpret the results of solving practical problems with computers and accept these results in practical activities.

These requirements, taken in the minimum volume, were the task of achieving the first level of computer literacy. Among those, taken in the maximum volume, were the education of the information culture.

Thus, the first interpretation of "information culture" only expanded the components of computer literacy. 
In connection with the early study of computer science, it became possible to systematically use the methods and means of new information technologies in the study of all school subjects. This factor made it possible to redistribute the learning objectives and move from the formation of computer literacy to the formation of the information culture of not only students in general educational institutions but also specialists with higher and professional education.

Since 1995, the term "information culture" has undergone a large number of interpretations. It was interpreted mainly through the ability to purposefully work with information and use computer information technologies, modern technical means and methods to obtain, process and transmit it. The information culture of a member of the modern information society can be defined as a relatively holistic system of professional and general human culture, associated with them in single categories (a culture of thinking, behaviour, communication, and activity) and including the following components:

- acceptance at the personal level of the humanistic value of human information activities;

- a culture of communication and cooperation in the field of computer science and information technology, the use of telecommunications for interpersonal and collective interaction, moral behaviour in the field of information relations;

- competence and free orientation in the field of information technology, flexibility and adaptability of thinking, behaviour, communication and human activities;

- the culture of communication and cooperation in the field of informatics and information technology, the use of telecommunications for interpersonal and collective interaction, moral behaviour in the field of information relations;

- competence, free orientation in the field of information technology, flexibility and adaptability of thinking;

- prediction of the possible consequences of information activities, professional, social adaptation in constantly updated information conditions;

- the use of ICT for the most effective solution of professional tasks;

- knowledge and implementation of the basic legal norms of regulation of information relations, awareness of responsibility for actions using ICT tools.

From the point of view of training a modern specialist, his information culture includes the following aspects:

- worldview, suggesting awareness of the impact of information technology on the development of modern society and the education system; 
- general educational, aimed at mastering the methods of working on a computer using modern software and information technology as a tool for educational and research activities;

- professional, suggesting the effective use of information technology in professional activities.

The basis of the competency-based approach is the idea of the need to move from declarative knowledge as the dominant characteristic to the transfer of experience, the formation of abilities and personal qualities of the totality, that is, competence (Kuznitsov, 2015, p. 27).

According to the competency-based approach, the primary information and communication competencies of a modern specialist are:

- competence in the field of information and analytical activities;

- understanding the role of information in human life and society;

- knowledge of the basic interpretations of information, their influence on the formation of a modern picture of the world;

- the ability to take into account the patterns of practice of information processes of their activities;

- possession of the skills of analysis and evaluation of information from the standpoint of its properties, practical and personal significance;

- competence in the field of cognitive activity: understanding the essence of the information approach in the study of objects of various nature; knowledge of the main stages of system-information analysis; possession of basic intellectual operations, such as analysis, comparison, generalization, synthesis, formalization of information, identification of cause and effect relationships and others; the formation of a certain level of system-analytical, logic-combinatorial and algorithmic thinking styles; the ability to generate ideas and determine the means necessary for their implementation;

- competence in the field of communication: attitudes towards languages (natural, formalized, formal) as a means of communication; understanding of the use of formal languages; knowledge of modern means of communication and the most important characteristics of communication channels; possession of fixed telecommunications facilities; knowledge of ethnic norms of communication and the main provisions of legal informatics;

- technological competence: understanding the essence of the technological approach to the organization of activities; knowledge of the features of automated technologies of information activity; the ability to identify the main stages and operations 
in the technology of solving problems, in particular with the help of automation; skills in performing unified operations, which form the basis of various information technologies;

- competence in the field of technical knowledge (technical competence): understanding of the operating principles, capabilities and limitations of technical devices designed for automated information processing, knowledge of the differences between automated and automatic execution of information processes; the ability to evaluate the class of tasks that can be solved using a specific technical device, depending on its main characteristics;

- competence in the field of social activity and generational succession: understanding the need to care for the preservation and enhancement of public information resources; willingness and ability to bear personal responsibility for the accuracy of the information distributed; respect for the rights of others and the ability to assert their rights in matters of personal information security;

- communication competence: understanding the processes of transmission and accumulation of information flowing in networks; the ability to use electronic network resources in professional activities.

\subsection{MEDIA EDUCATION AND MEDIA LITERACY}

Recently, in addition to the concepts of "information culture" and "information and communication competence", the terms "media education" and "media literacy" have become widespread.

The term "media" (from Latin media - means) is used as an analogue of the term "mass media" (print, photography, radio, cinema, television, video, multimedia computer systems, the Internet).

As in pedagogical science as a whole, so in media educations, there is no uniform terminology accepted in all countries of the world. As a rule, not only national scientific schools but also individual scientists from different countries offer their own options for formulating such key concepts as "media education", "media culture", and "media literacy". For example, in UNESCO documents, media education is understood as teaching theory and practical skills for mastering modern media of communication, considered as part of a specific and autonomous field in pedagogical theory and practice. Media education is regarded as a process of personal development using and on the basis of mass media (media) to create a culture of communication with the media of creative, communicative abilities, critical thinking, the skills of full perception, 
interpretation, analysis and evaluation of media texts, learning various forms of selfexpression using media technicians.

The UNESCO recommendation emphasizes that media education is part of every citizen's fundamental right to freedom of expression and information. Along with recognising differences in approaches and the development of media education in different countries, it is recommended that it be introduced wherever possible national curricula, as part of additional non-formal education and self-education throughout a person's life.

Media education is associated with all media types (print and graphic, sound, screen and so on) and various technologies. It makes it possible to understand how mass communication is used in societies, to master the abilities to use media in communication with other people, and provides a person with knowledge of how;

- analyze and critically interpret and create media texts;

- identify the sources of media texts, their political, social, commercial and cultural interests;

- interpret media texts and values shared by the media;

- select the appropriate media to create and disseminate their own media texts and gain the audience's interest in them;

- get the opportunity of free access to media both for perception and products.

Media education can be divided into the following areas:

1. Media education of future professionals in the world of the press, radio, television, cinema, video and the Internet - journalists, editors, directors, producers, actors, camera operators and others;

2. Media education as part of the general education of schoolchildren and students studying in ordinary schools, secondary specialized educational institutions, universities, which, for its part, can be integrated traditional disciplines or autonomous (special, optional, circle, etc.);

3. Media education in the process of advanced training of teachers of universities and schools in courses on media culture;

4. Media education in institutions of additional education and leisure centres (cultural centres, centres of extracurricular work, aesthetic and artistic education, in clubs in the community, etc.);

5. Remote media education of schoolchildren, students and adults using the press, television, radio, video, DVD, the Internet; 
6. Independent non-stop media education, which can be carried out throughout a person's life.

Media education provides a methodology for conducting classes based on a problematic, heuristic, game and other productive forms of training that develop the individuality of the student, the independence of his thinking, stimulate his abilities through direct involvement in creative activity, perceptions, interpretation and analysis of the structure of media text, assimilation of knowledge about media culture. At the same time, media education, combining lectures and practical classes, is a kind of inclusion of students in the process of creating a work of media culture; that is, it immerses the audience in the internal laboratory of the main media professions, which is possible both in stand-alone mode and in the process of integration into traditional academic subjects. Pupils and students should study not only how these or those media texts are constructed, but also how they express various political, ideological, economic, sociocultural interests (Henner, 2008, p. 81).

The concept of media literacy originates from the terms "critical vision" and "visual literacy", which have been used concerning on-screen media in the past decades. The terms "technological literacy", "information literacy", and "computer literacy" are also found in the scientific literature. Scientists from different countries (L. Masterman, K. Versnob, A. V. Sharikov, A. V. Spichkin) believe that media literacy is part of a broader and more comprehensive concept of "media education". Most UNESCO experts believe that the following media literacy is most founded: "Media literacy is a movement designed to help people understand, create and appreciate the cultural significance of audiovisual and printed texts. Media literate and individual can analyze, evaluate and create print and electronic media texts."

In this case, the following principles of media education should be considered:

1. The central concept of media education is representation: media do not reflect reality but represent it using a system of signs and symbols;

2. Media education is a research process, more a dialogue than a discussion;

3. Education in media education is based on the use of various analytical tools and many new ways of activities in multiple fields;

4. two criteria can assess the effectiveness of media education: the ability of students to apply their critical thinking in new situations and the amount of commitment and motivation they express concerning the media; 
5. Media education is a particular area in which knowledge is not simply transmitted by teachers or "revealed" to students. This is the subject of critical research and dialogue, during which teachers and students actively acquire new knowledge.

Media literacy helps students communicate with the media from a critical angle, understanding the importance of media in their lives. The formation of media literacy should provide the learner with the opportunity:

- develop the abilities, knowledge and relationships necessary to analyze how media actively construct reality;

- gain knowledge of the social, cultural, political and economic significance of these designs and the values they dispose of;

- develop a level of assessment and aesthetic perception of media texts;

- decode media texts to recognize and evaluate cultural values, practical significance, ideas contained in them;

- Recognize, analyze and apply a variety of technical uses and the creation of media texts.

Noting what new interactive opportunities for practical and analytical work are opening up for media education in connection with the spread of multimedia technology and the Internet, experts see in this process positive and negative aspects. The positive side is that in the computer class, you can be productively engaged in practical work. Therefore, many conceptual issues (for example, image manipulation) can be studied practically and understandably. On the other hand, such technologies can potentially individualize the process of creating media products, that is, isolate a person from society. Therefore, when teaching, it is assumed that students should study media theses, putting them in an extensive sociocultural context, not to break away from real life, but to participate in it actively.

Conclusions In the future education process will achieve maximum benefits if society can effectively use new information technologies - software and hardware tools and devices that operate based on computer technology, modern means of information exchange systems, providing operations for the collection, accumulation, storage, processing, the transmission of information. In the context of contemporary society's global problems (environmental, social, resource, informational), education should be aimed at comprehensive training of a specialist, their media education and media literacy mastering basic knowledge from various fields. One of the education system's answers to this request of time is the idea of competency-based education, expressed by many experts in the field of education informatization. Therefore, today the place of term 
"information culture" is more often used as the term "information and communication competence", which emphasizes that the process of informatization of a society substantially depends on the level of competence of its members in the field of information and communication technology.

\section{References}

\section{Books}

Robert, I. V. (2014) Teoriya i metodika informatizatsii obrazovaniya (Theory and methodology of education informatization, in Russian). Moskva: BINOM. Laboratoriya znanii

Khenner, E, K (2008) Formirovanie IKT- kompetentnosti uchashixsya I prepodavateley v systeme nepererivnogo obrazovaniya (Formation of ICT competence of students and teachers in the continuous education system, in Russian ). Moskva: BINOM. Laboratoriya znanii

\section{Journal}

Kuznitsov A. A (2015). Osnovnie napravleniya podgotovki rabotnikov cictemi obrazovaniya $\mathrm{k}$ ispolzovaniyu wev-resursov dlya profeccionalnogo camoobrazovanie(Basic directions of training educators in employing web-resources for professional self-development, in Russian). Informatika i obrazovanie, 1(260), 24-32

\section{Web Pages}

Gorokhova N. V. (2018). Informatization of education. Espacios, 39 (20). Retrieved Apr 18 , 2018 from:

http://www.revistaespacios.com/a18v39n20/a18v39n20p06.pdf 